\title{
Do museu de reproduções ao Museu das Origens: reflexões sobre projetos institucionais de Mário Pedrosa
}

\author{
Sabrina Parracho Sant'anna \\ Marcelo Ribeiro Vasconcelos ${ }^{2}$
}

\begin{abstract}
RESUMO
O artigo faz uma análise sobre a proposta de Mário Pedrosa para o Museu de Brasília (1958). O projeto, apresentado por Pedrosa por meio de uma carta enviada a Oscar Niemeyer, se caracteriza pela recusa em constituir um acervo próprio de obras de arte e pela intenção de utilizar em suas exposições e projetos didáticos reproduções de obras de arte. $\mathrm{O}$ artigo procurou estabelecer entendimentos sobre papel desempenhado por tal instituição dentro do projeto de Brasília, mas também como parte de um projeto estético mais amplo, em que eram privilegiadas as potencialidades comunicativas das artes visuais não figurativas, como o abstracionismo geométrico Para compreender como o projeto do museu de reproduções responderia às demandas históricas identificadas por Pedrosa a partir de sua interpretação sobre a função da arte moderna na construção de novas sensibilidades, foram estabelecidas comparações com outros dois projetos institucionais realizados e idealizados por Pedrosa: o Museo de la Solidaridad e o Museu das Origens.
\end{abstract}

Palavras-chave: Mário Pedrosa; museus; Brasília; arte; educação.

\section{From the museum of reproductions to the "Museu das Origens": reflections on Mário Pedrosa's institutional projects}

\begin{abstract}
The article analyzes the proposal of Mario Pedrosa for the Brasília Museum (1958). The project was presented by Pedrosa through a letter sent to Oscar Niemeyer and was characterized by the refusal to create its own collection of works of art and by the intention to use reproductions of works of art in its exhibitions and didactic projects. The article sought to establish understandings about the role played by such an institution within the Brasilia project, but also as part of a broader aesthetic project, in which the communicative potential of non-figurative visual arts, such as geometric abstractionism, was privileged. In order to understand how this museum of reproductions would respond to the historical demands identified by Pedrosa from his interpretation of the role of modern art in the construction of new sensibilities, comparisons were established with two other institutional projects carried out and idealized by Pedrosa: the "Museo de la Solidaridad" and the "Museu das Origens"
\end{abstract}

Keywords: Mário Pedrosa; museums; Brasília; art; education.

\footnotetext{
${ }^{1}$ Professora associada do Departamento de Ciências Sociais da UFRRJ e professora permanente do Programa de Pós-graduação em Ciências Sociais da mesma instituição. E-mail: saparracho@gmail.com

2 Professor colaborador do Programa de Pós-graduação em Artes, Cultura e Linguagem da Universidade Federal de Juiz de Fora. Doutor em sociologia pela Universidade Estadual de Campinas (IFCHUNICAMP). E-mail:marcelo.ribeiro84@gmail.com.
} 


\section{Introdução}

Em tempos de quarentena e isolamento social por covid-19, quando a circulação cotidiana está interrompida e a cultura se fecha sobre si mesma a procura de novos meios de difusão ${ }^{3}$, museus e espaços expositivos retomam antigos debates sobre as possibilidades do uso de tecnologias para ampliação do acesso às obras de arte. De fato, não apenas momentos críticos, como o recente incêndio do Museu Nacional e a discussão sobre o uso de impressoras 3D para a reconstituição de réplicas, mas também o uso intensivo de imagens reproduzidas em museus de tecnologia, apontam para a atualidade de um debate que não vem de hoje. Entre os projetos museais em que Mário Pedrosa esteve envolvido, o projeto de 1958 para o Museu de Arte de Brasília parece especialmente oportuno para a reflexão hodierna.

Como é sabido, para além de sua atuação na vida política brasileira e na crítica de arte, Pedrosa se dedicou intensamente a projetos de institucionalização da arte, tanto em âmbito nacional, como internacional (PUCU, 2019). Já foi objeto de análise sua conhecida participação na fundação do Museu de Arte Moderna do Rio de Janeiro em meados do século XX (SANT'ANNA, 2011), na reformulação do MAM após o incêndio em 1978 (SANT'ANNA, 2014; LOPES, 2013.), na criação do Museu da Solidariedade no Chile (CACERES, 2010; LOPEZ, 2010). No entanto, dentro do que se poderia chamar de um projeto para arte e educação de Pedrosa, o museu de Brasília foi ainda muito pouco debatido. De fato, além da relevante contribuição de Quinderé (2018), o museu de Brasília pouco ocupou as reflexões daqueles que pesquisam sua obra. Talvez por que o projeto abandonado pouca repercussão tenha tido no momento de sua formulação, talvez por que o debate em torno dele pouco tenha ocupado a agenda pública naquele momento e faltem dados para uma compreensão mais detalhada sobre seu fracasso. De todo modo, partimos do pressuposto de que projetos silenciados também ordenam a vida social e reaparecem quando passam a responder às questões postas no horizonte de expectativas de épocas porvir (JAUSS,1994). Nesse

\footnotetext{
3 Even during COVID-19, art 'brings us closer together than ever' - UN cultural agency.
} https://news.un.org/en/story/2020/04/1061802 
sentido, vale a pena retomar o projeto de Pedrosa, do ponto de vista da rede discursiva que acionava no momento de sua formulação e, sobretudo, dos projetos de arte e educação que formulava então.

\section{O projeto do Museu de Brasília: referências e silêncios}

Em carta endereçada a Oscar Niemeyer, em 24 de julho de 1958, Pedrosa evocava trocas de ideias anteriores sobre o Museu de Brasília e punha por escrito como deveria ser uma tal instituição. A correspondência, preservada nos arquivos CEMAP, foi publicada por Otília Arantes em Política das Artes (1995) e tanto expressa muito claramente o projeto do museu, como aponta para visões mais amplas sobre o que Pedrosa compreendia pela relação arte e educação e para sua compreensão do papel de Brasília na constituição de um novo país. Na imprensa, o projeto teve pouca repercussão. No entanto, no Correio da Manhã, a coluna de Jayme Maurício de o6 de agosto de 1958, incluía nota anunciando que Juscelino Kubitschek autorizara Oscar Niemeyer "a combinar oficialmente com o crítico Mário Pedrosa a organização de um museu de reproduções em Brasília” (MAURÍCIO, 1958, p.12).

$\mathrm{Na}$ carta a Niemeyer, a proposta se iniciava enumerando as dificuldades para criação de um novo museu de arte na cidade e apontando as falhas dos inúmeros projetos que povoavam, então, o país. Num olhar retrospectivo, Pedrosa olhava para as instituições que havia visto serem criados naquela década e apontava suas ausências. Os esforços para criação dos museus de arte moderna no Rio e em São Paulo e, sobretudo, do MASP eram, então, revisados. Segundo Pedrosa:

\footnotetext{
O resultado é que há de ser sempre um museu 'à americana', isto é, incompleto nas suas coleções quanto a uma autêntica representação por escolas e arte do passado, e híbrido, quer dizer, sem uma especialização caracterizada, de nível verdadeiramente histórico e científico (PEDROSA, 1995a, p.287-288).
}

Diante da construção da nova capital, Pedrosa remetia ainda às dificuldades da realidade sui generis de sua localização espacial. Numa "cidade apenas em formação - e que em formação ainda estará durante muito tempo”, Brasília estava “isolada dos 
grandes centros culturais" e "só muito dificilmente poderia aproximar-se do nível dos congêneres das duas velhas capitais, apesar de enormes somas, a serem contadas por milhões e milhões, que o governo quisesse ou pudesse investir, continuamente, para constituir-lhe o acervo" (PEDROSA, 1995a, p.288). Não eram apenas os obstáculos concretos, no entanto, que ordenavam as preocupações de Pedrosa. Como discutido em outras ocasiões, Pedrosa concebera "Brasília como uma continuidade do projeto estético que procurava defender no Brasil" (RIBEIRO VASCONCELOS, 2019, p.36) O projeto de fundação da nova capital, ao lado do projeto construtivo de Pedrosa, possibilitava "melhorar a qualidade artesanal e mesmo estética de nossas artes" em razão de uma "autodisciplina" e de um "espírito menos complacente consigo mesmo" (PEDROSA, 1959a).

Assim também, o museu digno da nova capital não poderia ser construído "nos moldes tradicionais, caracterizado por sua coleção de obras originais". Ao contrário, seria "todo ele um museu de cópias, reproduções fotográficas, moldagens de toda espécie, maquetes, etc.” (PEDROSA, 1995a, p.288). Orientado para a maior completude possível, o museu se dedicaria à apresentação de "todos os ciclos da história da arte mundial”. Sem falhas ou omissões se voltaria "às manifestações artísticas das diversas civilizações e culturas históricas e aos diversos movimentos que definem a arte contemporânea" (Idem). Acompanhadas de projeções de slides e textos explicativos gravados, as exposições de ciclos históricos estariam também integradas a uma filmoteca e cursos de iniciação artística.

Em 1958, Pedrosa ecoava discussões que grassaram no debate sobre o uso das técnicas de reprodução na democratização do acesso à arte, a partir dos projetos de reconstrução pela cultura que se seguiram às duas grandes guerras (COSTA, 2015). Pioneiro no Brasil nesse debate, Mário de Andrade publicara em 1938, texto sobre museus populares em que defendia que: "Em vez de tortuosos museus de belas-artes, cheios de quadros verdadeiros de pintores medíocres, com menos dinheiro abramos museus populares de ótimas reproduções feitas por meios mecânicos" (ANDRADE, 1938). Escrito no período em que atuava como diretor do Departamento Municipal de Cultura de São Paulo, o texto de Mário de Andrade, com quem Pedrosa travou intensa correspondência em seus anos de formação (FORMIGA, 2014), expressa algumas das 
questões que ecoavam no projeto do museu de Brasília. O autor de Macunaíma, que sabidamente saíra do Brasil apenas para Iquitos e conhecera as obras da cultura mundial pelas reproduções que lhe chegaram nos livros, argumentava ainda em favor do potencial transformador dos museus (LOURENÇO, 2002):

Mas é que o verdadeiro museu não ensina a repetir o passado, porém a tirar dele tudo o quanto ele nos dá dinamicamente para avançar em cultura dentro de nós, e em transformação dentro do progresso social (ANDRADE, 1938).

A ideia de formação e transformação social pela arte, de fato, era cara também a Pedrosa e aparecia em outros projetos baseados em técnicas de reprodução com que o crítico havia tido contato. São, decerto, dignas de nota as experiências do MoMA de Nova York na difusão da arte moderna a partir da exposição itinerante What's Modern Painting, que circulou pelos Estados Unidos na década de 1940. De fato, o departamento educativo do Museu de Arte Moderna nova iorquino, do qual Victor D’Amico esteve à frente a partir de 1937, serviria, por exemplo, de inspiração para o projeto de Pedrosa e Niomar Moniz Sodré para o MAM carioca, a partir de 1951. Ainda que a questão da formação do artista, negligenciada por D’Amico, estivesse no cerne do projeto sediado no Rio de Janeiro, a transformação pela arte, e sobretudo pela arte moderna, era questão central para os dois museus (SANT'ANNA, 2011). ${ }^{4}$

Ainda com respeito às exposições itinerantes, cabe ressaltar o papel da UNESCO na consolidação do uso das técnicas de reprodução para difusão da arte. Helouise Costa ressalta, por exemplo, a primeira exposição itinerante da UNESCO, montada entre 1948 e 1949 com 50 reproduções coloridas, "From Impressionism to Today", e chama a atenção também para o "Catálogo de reproduções coloridas de pinturas a partir de 1860", publicado em 1950 e que seria o primeiro de uma série

\footnotetext{
${ }^{4}$ Decerto a crença no papel formativo dos museus e num poder transformador da arte moderna também eram elementos presentes no projeto do Museu de Brasília e nos demais projetos institucionais citados aqui. Tendo em vista a participação de Pedrosa no MAM-RJ ao longo da década de 1950 e sua atuação como diretor do MAM-SP (1961-1963), parece pertinente abordar possíveis confluências entre tais experiências e o projeto de Pedrosa para Brasília. Mas como já foi apontado anteriormente, a carta de Pedrosa a Niemeyer procurou exatamente marcar a diferença entre o museu de reproduções e instituições museais já estabelecidas, enfatizando as condições únicas enfrentadas pelo museu planejado para a nova capital. Como o intuito do artigo é compreender o sentido de um museu de reproduções no contexto de Brasília e em um projeto estético pedrosiano, privilegiou-se o estabelecimento de comparações com outros projetos institucionais idealizados por Pedrosa.
} 
(COSTA,2015). De fato, em sua carta a Niemeyer, Pedrosa remetia, por sua vez, ao museu de reproduções em Beirute, organizado pela UNESCO, e retomava ainda a tentativa de construir uma instituição congênere em São Paulo, projetada, em 1953, para as comemorações do IV Centenário da cidade. O projeto para o IV Centenário contara, segundo Pedrosa, com participação de Herbert Read e Ernesto Rogers, mas não fora levado adiante por "motivos de ordem financeira” (PEDROSA, 1995a, p.292).

Com efeito, em 1953, nos registros do IV Congresso da Associação de Críticos de Arte, em Dublin, ao qual Pedrosa comparecera com comunicação sobre as relações entre arte e ciência, James Johnson Sweeney fizera longa defesa dos filmes de arte como meio de difusão da crítica. Também Jean Leymarie mencionara expressamente o conceito de museu imaginário que dizia, então, em voga. O congresso de 1953 chama, portanto, a atenção para o uso das técnicas de reprodução na difusão da arte e da cultura, uma questão que seria cara a Pedrosa no projeto de Brasília.

Também na imprensa brasileira, o debate sobre museus de reproduções se alargava pela recepção da obra de André Malraux. Publicado em 1947, o Museu Imaginário de Malraux difundia pelo mundo, juntamente com o nome do autor que ganhava crescente notoriedade, o uso intensivo das reproduções para difusão do conhecimento da arte. Diante dos museus sempre incompletos, Malraux argumentava que as reproduções das obras de arte criavam um museu imaginário capaz de "aprofundar ao máximo o incompleto confronto imposto pelos verdadeiros museus". Segundo ele, respondendo ao apelo por estes lançado, "as artes plásticas inventaram a sua imprensa" (MALRAUX, 2000, p.14).

Em levantamento no Correio da Manhã o nome de Malraux é recorrentemente citado, ao lado de Camus, como um dos principais expoentes das letras na França. Como Ministro da Informação (1945-1946) e mais tarde Ministro de Assuntos Culturais (1959-1969) de De Gaulle, o nome de Malraux alcançava ainda com maior frequência as manchetes dos jornais. Por exemplo, em 1956, Murilo Mendes, em entrevista a Jayme Maurício por ocasião da Campanha Internacional de Museus, promovida pela UNESCO, fazia referência explícita ao projeto de Malraux. A manchete que encabeçava a coluna de Jayme Maurício, "Museu, necessidade vital", coincidia com a célebre conferência de Pedrosa “Arte, necessidade vital”, proferida quase uma década antes no 
salão do Ministério da Educação e Saúde, e publicada naquele mesmo jornal. Na entrevista, Murilo Mendes defendia o museu de reproduções como "fórmula capaz de romper as barreiras ainda existentes entre a alta arte e o grande público" e lembrava que "no breve período em que foi ministro da educação no governo De Gaulle, André Malraux propusera que todas as escolas de França possuíssem, para começo de conversa, cem reproduções de obras fundamentais de pintura e escultura" (MAURÍCIO, 1956).

De fato, naquele momento o nome de Malraux, que concorrera com Camus ao Prêmio Nobel de 1957, circulava com frequência na imprensa brasileira. Em 1959, pela proximidade de sua visita ao Brasil, já como Ministro de Assuntos Culturais, o nome de Malraux aparece em 123 ocorrências no Correio da Manhã. Na coluna de Jayme Maurício, seu nome chega a ser mencionado entre os críticos que acorreriam à célebre conferência da AICA, organizada por Pedrosa em Brasília (MAURÍCIO, 1959). A visita acabaria se dando um mês antes da conferência, mas também contaria com visita de Malraux à capital em construção. Seu nome estava, de fato, inscrito no horizonte de expectativas da época e contribuiu para conferir legitimidade ao uso das técnicas de reprodução na difusão da arte.

No período, no entanto, as menções de Pedrosa a seu nome se restringem à lista de delegados convidados à AICA, divulgada em 1959. Ao contrário da coluna de Jayme Maurício, pródiga na publicação de menções ao autor, as críticas de Pedrosa publicadas no Correio da Manhã ou no Jornal do Brasil silenciam sobre Malraux na década de 1950. Em 1948, Pedrosa já deixara claras suas divergências em relação ao autor, quando publicara o texto "Meu encontro com Malraux", no Correio da Manhã. Ainda que reabilitado pela Partisan Review, de que Pedrosa se aproximara nos primeiros anos de seu exílio nos EUA (RIBEIRO VASCONCELOS, 2018), Malraux era visto com restrições pelo crítico. A participação de ambos no mesmo círculo internacional de intelectuais anti-stalinistas certamente facilitara a realização da entrevista publicada no Correio da Manhã, mas havia dentro deste grupo uma clara clivagem entre aqueles que defendiam a construção de outro modelo socialista, de caráter democrático, e aqueles que se voltaram abertamente para o anticomunismo. $\mathrm{O}$ 
fato de Pedrosa e Malraux estarem à época em polos opostos de tal clivagem ajuda a compreender o tom mais cauteloso de Pedrosa ao descrevê-lo naquela ocasião.

No artigo, Pedrosa descreve Malraux como alguém que impõe a si mesmo a necessidade de dar explicações. Situado, no início do artigo, em comício diante da multidão entusiasmada de gaullistas que o ouvem, o Malraux descrito por Pedrosa é, em seguida, caracterizado pela guinada biográfica de quem deve satisfações à própria história: "Sente entretanto ser preciso dar 'satisfações', e isso o aborrece. Talvez humilhe.”. O afastamento da causa operária e a aproximação de um governo à direita fazem transparecer a decepção de Pedrosa e suas divergências em relação ao autor. Descrevendo as sucessivas incursões de Malraux na vida política internacional - na causa anticolonial na Indochina, na Guerra Civil Espanhola, na Resistência francesa Pedrosa lhe atribui uma personalidade movida pela ação e entregue ao destino. Em lugar da decisão deliberada e humana que define o domínio sobre a natureza e dá forma ao curso da própria vida, Malraux estaria entregue às moiras e ao sabor dos acontecimentos históricos:

\footnotetext{
A meditação malrauviana é impregnada desse sentido trágico do destino. Este realmente domina o desinteresse e o jogo criador do artista. A nossa época oferece em abundância o drama de que carece a sua imaginação, mas precisamente porque o oferece perdulariamente, o artista tende a apagar-se, dispensando-se do criar, e o homem prefere render-se ao destino do que reagir para ser livre na distância e na perspectiva (PEDROSA,1948).
}

De fato, é digno de nota que, em seus projetos museais, Pedrosa saliente de maneira enfática a capacidade de transformação das percepções pela forma artística, mas uma transformação que é necessariamente reflexiva. Assim também, dez anos mais tarde ao conceber o Museu de Brasília, Pedrosa impõe a necessidade de acrescentar ao projeto "bancos para reflexão e contemplação", como um momento de introspecção para elaboração da experiência vivida: "Nesse sentido, seria ainda conveniente que fosse proporcionada ao visitante a possibilidade de, após alguns ciclos, ir ao exterior, descansar espairecer, meditar sobre o que viu" (PEDROSA, 1995a, p.293). Embora a menção aos momentos de introspecção seja breve, é digno de nota que sua necessidade seja expressa na carta tão sucinta. De fato, se Pedrosa 
contrapunha na personalidade de Malraux ação e reflexão, seu projeto colocava ênfase no ponto que dizia faltar ao autor gaullista. De fato, embora tenha tomado posição nos principais acontecimentos políticos do século XX, Pedrosa marcava sua perspectiva pelo caráter autorreflexivo de sua produção e de uma crítica que incorporava em diálogo interior as mudanças rápidas e profundas pelas quais passava o mundo em que vivia (SANT'ANNA, 2019). De fato, Pedrosa levava para seus projetos de museu a crença na arte como processo de reflexão, imaginação, criação e transformação, como dissera também Mário de Andrade em seu texto de 1938.

\section{Gestalt, comunicação e educação no fenômeno artístico.}

Desde o seu encontro com Malraux em Paris até suas proposições sobre o museu de Brasília, Pedrosa estabeleceu uma profícua trajetória na crítica de arte. Desde 1945, ano de seu retorno ao Brasil após cerca de sete anos de exílio, Pedrosa produziu um pensamento em artes visuais que impactou artistas e instituições brasileiras. Mas como o projeto de museu para a Brasília se encaixaria em tal projeto?

Um primeiro ponto que deve ser considerado é que a proposta de um museu de reproduções parece, à primeira vista, divergir da produção crítica de Pedrosa no período. Tal impressão é reforçada, principalmente, se for observada apenas a tese de 1949, "Da Natureza Afetiva da Forma na Obra de Arte”. Nesta, Pedrosa enfatizou a análise dos elementos objetivos que conduziriam a experiência artística, estabelecendo como um dos princípios de tais experiências uma homologia entre as qualidades formais da obra e as estruturas cognitivas dos sujeitos impressas no próprio sistema nervoso do indivíduo. A partir de tal perspectiva baseada na Gestalttheorie, as reações afetivas do espectador da arte poderiam e deveriam se manifestar sem a mediação de preocupações analíticas e significativas, que acabariam por embotar a força das impressões estéticas (ARANTES, 1979).

Mas tal preocupação com uma fundamentação biológica do fenômeno artístico não determinaria nem a psicologia da forma e nem abordagem pedrosiana sobre as artes visuais. Sobre a Gestalt, Paul Guillaume deixa claro em La psychologie de la forme (1937), uma das obras citadas por Pedrosa em sua tese, que tal teoria não ignora "a 
experiência vivida pelo sujeito” (GUILLAUME, 1966, p.176). Segundo o autor, o essencial da Gestalt seria exatamente "determinar como o sujeito percebe a situação na qual está colocado", procurando não apenas observar os vínculos inteligíveis entre os estímulos do meio e as respostas biológicas e cognitivas dos sujeitos, mas, sobretudo, estabelecer "como a constelação objetiva dos estímulos condiciona a organização perceptiva e com esta, por sua vez, reflete-se na organização da reação” (Idem). Da mesma maneira, Pedrosa parece ter se interessado, nesse momento, pelas qualidades fisionômicas que orientariam o fenômeno artístico em razão da busca por fundamentações teóricas que permitissem uma contraposição à tendência subjetivista que observara nas vanguardas artísticas e na crítica norte-americanas 5 e, também, como uma justificação estética de sua defesa do caráter artístico dos trabalhos dos internos do Ateliê do Engenho de Dentro. ${ }^{6}$

Apesar de parecerem motivações distintas, a rejeição ao excessivo subjetivismo e às críticas daqueles que não viam nas pinturas de Raphael e Emygdio a manifestação de uma vontade artística $^{7}$ se encontravam na busca pedrosiana pelos caminhos possíveis para se alcançar a "boa forma", isto é, "a força coordenadora interna que prenuncia o dinamismo das mais altas atividades mentais (...) [que] exerce-se interiormente, graças a forças dinâmicas autônomas que se manifestam na dialética de todos e das partes nele integradas e a ele subordinadas" (PEDROSA, 1979a, p.21). Nos

\footnotetext{
${ }^{5} \mathrm{O}$ surgimento e o desenvolvimento do expressionismo abstrato no pós $2^{\underline{a}}$ Guerra Mundial pode ser relacionado ao processo de "de-marxização" de artistas e críticos participantes dos círculos da esquerda anti-stalinista norte-americana (GUILBAUT, 1983). Em um esforço de se distanciar tanto das ideologias de esquerda e de direita, estes teriam estabelecido um movimento de vanguarda que afirmava a recusa modernista ao mercado e colocava como único "comprometimento" radical possível ao artista moderno a liberdade individual e a expressão de impulsos subjetivos que só se manifestariam diante da alienação do artista em relação ao restante da sociedade. De acordo com Harold Rosenberg, um dos principais críticos vinculado à nova pintura norte-americana, esta nova postura estabelecia a pintura enquanto um "ato" que se constitui enquanto arte na medida em que "traduz o que é fornecido psicologicamente para o intencional, para um 'mundo' e, deste modo, o transcende" (ROSENBERG, 1951).

${ }^{6}$ Foi em sua defesa sobre o caráter artístico da produção dos internos do Ateliê do Engenho de Dentro que Pedrosa demonstrou suas posições sobre a ordenação objetiva da experiência estética e sua universalidade, assim como a sua recusa a uma concepção de arte como uma projeção livre de emoções. Tais crenças ampararam, de diferentes maneiras, os projetos institucionais idealizados por Pedrosa. Sobre a relação entre Mário Pedrosa e o Ateliê do Engenho de Dentro, ver VILLAS BÔAS, 2008.

7 A principal polêmica em torno da defesa do caráter artístico da produção dos internos que participavam do ateliê se deu entre Pedrosa e o crítico Quirino Campofiorito. Sobre tal polêmica, ver DIONISIO, 2012.
} 
primeiros, a recusa se dá pela crença na necessidade de conduzir conscientemente e objetivamente os processos imanentes a tal princípio, enquanto nos demais tal recusa se dá pela crença na possibilidade que tal "boa forma" possa ser alcançada espontaneamente.

Ao longo da década de 1950, Pedrosa desenvolveu sua abordagem sobre a Gestalt, agregando outras ideias e debates. Compreender o sentido que a proposta de museu de Brasília possui no interior da visão de Pedrosa deve considerar o lugar de um museu deste tipo nessas reflexões, assim como a incorporação de autores como Maurice Merleau-Ponty, Suzanne Langer, Ernst Cassirer, Herbert Read a tal interpretação sobre o fenômeno artístico. Mas é importante também ter em vista que o fato de o museu de reproduções ter sido planejado como parte do projeto de construção de Brasília também é um elemento importante para compreender o papel de tal museu em um projeto civilizatório que Pedrosa visionava para o Brasil. Se visto como parte de tal projeto, o museu de Brasília, assim como a nova capital e a própria arte moderna abstracionista, ganham um caráter social - ou até mesmo político. Em um período de "barbarização progressiva", ${ }^{8}$ a arte moderna deveria assumir uma nova função, capaz de desempenhar um poderoso papel no interior do "conflito aberto nos limites perceptivos do indivíduo numa sociedade de massa" (ARANTES, 1996, p.10). Em tal contexto, caberia aos artistas abstratos, "os mais conscientes da época histórica em que vivem", a missão de "ampliar o campo da linguagem humana na pura percepção, nos limites do individual" (PEDROSA, 1957). Cabe então a pergunta: como um museu de reproduções contribuiria para tal missão?

Já em 1946, em uma série de artigos sobre o tema da função da arte, Mário Pedrosa abordava a importância da educação artística, concebendo-a não como um processo de formação de artistas e para a criação de obras, mas como uma educação

\footnotetext{
${ }^{8}$ Tal termo foi utilizado por Pedrosa em 1947 para descrever a realidade enfrentada pelos intelectuais e artistas do seu tempo. Ao utilizá-lo, Pedrosa parece, em primeiro lugar, identificar uma crise na cultura ocidental estabelecida pelo avanço de um processo de barbárie que se tornou evidente com a $2^{\underline{a}}$ Guerra Mundial. Contudo, tal termo também parece remeter ao fato de tal crise estar intimamente ligado à ideia de progresso estabelecido pela tradição ocidental e a consequente hipertrofia da burocracia e da técnica. Na mesma entrevista, Pedrosa diz: "o Estado nacional totalitário, no seu desenvolvimento perfeito, como na Rússia, ou ainda em evolução, como nos Estados Unidos, tem sua lógica impessoal, implacável que funciona com a perfeição da técnica moderna. Os cientistas vão sendo cada vez mais arregimentados tanto num país como no outro, e posto a serviço do 'grande patrão'. Este os quer para a fabricação de novas superatômicas e novíssimos gases venenosos” (PEDROSA, 1947).
} 
"dos sentidos e das emoções", que deveria, preferencialmente, "preceder a educação do intelecto e do espírito" e ensinar aos jovens aprendizes "a ver os objetos, a distinguir sons, a sentir a vida palpitante das coisas por si mesmas" (PEDROSA, 1946). O Museu de Brasília idealizado por Pedrosa parece proporcionar meios para contribuir com essa primeira educação em artes, mas não seria esse o objetivo do museu. A ênfase em textos explicativos, documentos, o uso de meios tecnológicos de instrução, a divisão espacial do museu em ciclos históricos e muitas das demais características do museu enumeradas por Pedrosa em sua carta a Niemeyer indicam que esse museu deveria atender a todo tipo de público.

Na mesma carta, Pedrosa cita uma tentativa anterior de organização de um museu do mesmo tipo, que deveria ser criado em São Paulo para as comemorações do seu IV Centenário. Segundo Pedrosa, a comissão que idealizou essa tentativa era constituída por ele, Herbert Read e Ernesto Rogers. Apesar de não terem sido encontrados dados sobre tal projeto e nem resultados alcançados por tal comissão, a informação presente na carta de Pedrosa nos indica que Read, autor com extensa produção em educação artística, colaborou no projeto de museu de reproduções, o que também é reforçado pelas várias aproximações entre tais obras e as posições de Pedrosa acerca da questão da arte e educação. Ao abordar a educação infantil, Read caracterizou a relação entre arte, educação e racionalidade enfatizada por Pedrosa como uma "experiência orgânica total”, vivenciada principalmente por crianças e pelos chamados "primitivos". Em tal experiência, não há uma evidente diferenciação entre a imagem e aquilo que é percebido, o que significaria a ausência de uma mediação de conceitos abstratos entre ambos. Nas sociedades modernas, essa experiência direta sobre a realidade se enfraqueceria e os indivíduos acabariam por estabelecer uma consciência partida, em que os conceitos acabam apartados das sensações. Nesta interpretação de Read, a arte aparece como uma das formas de restabelecer essa consciência integrada, o que pode ser prejudicado quando a arte é invadida por uma atitude excessivamente intelectual. Assim, tanto a arte como a educação teriam a possibilidade de preservar essa unidade da consciência e da percepção. 
O que agora é sugerido, em oposição a toda a tradição lógico-racionalista, é que existe um modo visual concreto de "pensar", um processo mental que atinge sua maior eficiência na criação do mundo da arte. É um modo de pensar que sustenta aquela unidade primária de percepção e sentimento encontrada na disposição eidética. Esta unidade primária se desenvolve na unidade de sensibilidade e razão (sensação e ideias) e é então a base de toda atividade imaginativa e prática (READ, 1958, p.69 [tradução dos autores]).

Anos depois, em 1953, elementos de tal debate foram retomados em "As relações entre a ciência e a arte”, trabalho apresentado no IV Congresso da AICA, realizado em Dublin. No artigo, Pedrosa enfatiza um ponto comum compartilhado tanto pela arte como pela ciência moderna: a independência em relação à natureza exterior e a experiência imediata. Tal autonomia teria permitido aos artistas finalmente se desvencilhar do "velho ferrete conceitual", permitindo a "recolocação do artista diante da coisa sensível, para que ele pudesse novamente manter com esta um diálogo sem intermediários verbais, sem associações conceituais alheias a ela" (PEDROSA, 1996, p.245). Para Pedrosa, em sua fase mais moderna, a arte poderia ser reivindicada como um meio de conhecimento assim como a ciência, pois agora ela seria capaz de "chegar a um pensamento articulado das essências, dos fundamentos do real que a ciência apreende, analisa e submete à sua crítica precisa" e tentar "trazer-nos novas concepções de objetos ideais, que se manteriam em um plano de analogia com as unidades formais de significação própria como as gestalts no mundo psicofísico e as estruturas físico-matemáticas" (PEDROSA, 1996, p.246). Como um modo de conhecimento autônomo, a arte se debruçaria exatamente sobre uma comunicação simbólica, ou um "simbolismo presentativo"9 que se caracterizaria por seu poder totalizador e intraduzível, em que a experiência sensível é imprescindível. Em sua diferença em relação à linguagem verbal, tal comunicação não poderia ser expressa por símbolos equivalentes, se manifestando apenas "por uma ação de presença direta”:

\footnotetext{
9 Pedrosa mobiliza aqui a noção de "simbolismo presentativo" em referência à Susanne K. Langer, que definiu tal conceito como um simbolismo sem palavras, não discursivo e intraduzível e que "não permite definições dentro de seu próprio sistema e não pode transmitir generalidades diretamente". Neste tipo de simbolismo, "os significados de todos os outros elementos simbólicos que compõem um símbolo maior e articulado são compreendidos apenas por meio do significado do todo, por meio de suas relações dentro da estrutura total", de modo que o funcionamento de tais símbolos depende do fato de estarem "envolvidos em uma apresentação integral e simultânea". Langer estabelece tal conceito com o intuito de caracterizar a distinção essencial entre o simbolismo presentativo e o simbolismo discursivo, ou seja, da "linguagem" propriamente dita.(LANGER, 1954, p.78-79).
} 


\begin{abstract}
Neste novo modo o conhecimento vem por descobertas; com efeito, deve-se descobrir, entre suas partes constituintes, entre suas estruturas parciais, ligações, aproximações súbitas, inesperadas ou impossíveis de atingir pelo desenvolvimento lógico, mas que nos dão, só elas e de uma vez, a significação do pensamento simbólico global presente. Este pensamento, esta ideia, não é demonstrativo e não apresenta nenhuma solução que se possa transferir, não sendo nunca, por outro lado, desmontável em suas partes. Mas é uma verdade, a verdade do nascimento de um novo ser. A contribuição deste conhecimento novo não é nunca uma lei, nem um conceito puro, está claro; mas, mais do que uma imagem, é um acontecimento. Assim, por este outro modo de pensamento simbólico, o campo do cognoscível é ampliado, e nós nos aproximamos um pouco mais da natureza das coisas, ou antes, do misterioso trabalho de elaboração formativa da natureza (PEDROSA, 1996, p.249).
\end{abstract}

Em 1953, Pedrosa argumentava, portanto, que a arte havia se desligado de suas peias seculares, tornando-se autônoma, um fim em si mesma, "un phénomène ésthetique tout court". Pondo-se como um meio de conhecimento próprio, rejeitando a mimesis da natureza, mas também relações diretas com outros saberes, a arte se punha, ainda sim, como testemunho de seu tempo. De fato, o conhecimento estético, que se dava como Gestalt, como um flash de revelação, deveria, no museu, se revestir de "caráter eminentemente pedagógico e documental" e exigia para, assim se realizar, projeções de slides, com textos explicativos gravados "a fim de que a finalidade instrutiva e educacional [fosse] melhor alcançada" (PEDROSA, 1996, p.292). Com efeito, também a relativa autonomia da arte deveria estar ali relacionada aos avanços da técnica que colocavam a arte como produto dos contemporâneos de seu tempo: "Os ciclos (...) serão providos de instalações para exemplificar inovações técnicas e industriais, novos materiais e meios de expressão, descobertas e invenções que exerceram influência sobre determinados estilos ou provocaram modificações ou interrupções no curso da evolução artística" (PEDROSA, 1996, p.293). Em Brasília, onde tudo era novo, o projeto de país moderno podia finalmente se realizar. A afetação da forma, manifesta tanto na arquitetura, como no entendimento de seu lugar na história da arte, faziam, portanto do museu, espaço privilegiado para a reflexão sobre a construção da nova cidade e um país condenado ao moderno. Como já discutido em ocasiões anteriores: 
Para Pedrosa, a força motriz de Brasília seria o espírito da utopia, capaz de, a partir do centro mesmo do país, criar uma nova região que fosse de fato moderna, construída "de alto a baixo" como "produto acabado da vontade consciente do homem", capaz de estabelecer uma nova forma de colonização que suplantasse aquele "espírito mercantilista do rei colonizador" que marcara a formação brasileira até então. Brasília se estabeleceria como marco e exemplo de uma nova geração no Brasil, que deveria povoar essa nova região sob o signo do ideal que levara à construção da nova capital (RIBEIRO VASCONCELOS, 2019, p.35).

\section{9, o Neoconcretismo e outros projetos museais de Pedrosa}

Estabelecido no período do deslocamento do crítico ao Japão, o diálogo de Pedrosa com Niemeyer era também contemporâneo de outros debates por ele travados. É especialmente digno de nota que correspondências foram trocadas, então, com os artistas que no mesmo período formulavam, no Rio de Janeiro, as bases da mais efetiva ruptura com o grupo concreto paulista. Em 16 de fevereiro de 1959, Ferreira Gullar escreveria a Pedrosa relatando o texto do manifesto neoconcreto que o grupo carioca publicaria em março daquele ano. Dizia Gullar:

\footnotetext{
Quanto ao neoconcretismo, mandaremos a você o manifesto. Você já deve imaginar do que se trata. O nome, antipático como sempre, é uma necessidade: pretendemos afirmar uma continuidade da arte não-figurativa construtiva, de Mondrian a nós (!), mas levando em conta mais as obras que a teoria. Consideramos certa identificação da arte e da ciência (transposição de conceitos científicos para o campo da arte) como uma necessidade de certa época que não se manifesta hoje. Pede-se assim uma nova interpretação dessa arte, na base dos valores expressivos (GULLAR, 1959).
}

Embora, em entrevista a Nina Galanternick, Gullar se refira à carta e ao movimento neoconcreto como um "golpe" dado na "ausência do papai grande", dirigido a Pedrosa justamente durante o período de seu afastamento no Japão, o poeta também reconhece que a leitura da fenomenologia de Merleau Ponty, ordenadora da ruptura no interior do movimento, foi recomendada a ele pelo próprio crítico (GULLAR, 2008). Ainda na mesma entrevista, Gullar reconhece, ademais, que Pedrosa adere às obras produzidas dentro dos novos preceitos e que reconhece também que o crítico não se opõe ao movimento que se desenvolveria nos meses seguintes. Mais que isso, vale ressaltar que há muito discutindo a autonomia da arte, Pedrosa já chamava a 
atenção para a independência entre arte e ciência como meios de conhecimento rivais e também para a distinção de interpretações no interior dos grupos concretistas sediados no Rio e em São Paulo (SANT'ANNA, 2004).

O que vale chamar a atenção, no entanto, é que se, dentro do projeto de Pedrosa para o museu, o passado histórico se erigia para concluir-se no núcleo da arte moderna, o advento do neoconcretismo e outras sucessivas rupturas na história da arte e da política brasileiras colocariam em questão o modelo sugerido para o Museu de Brasília em 1958. De fato, naquele ano, quando escrevia a Oscar Niemeyer, Pedrosa propunha que os núcleos históricos, que incluíam da "Pré-História" à "Época Moderna" e à "Arte dos Povos Primitivos Contemporâneos", se concluíssem na etapa contemporânea incluindo uma forma de arte que para Pedrosa se sintetizava na própria cidade. Ainda que trajetórias alternativas pudessem ser percorridas pelos visitantes, o percurso antevia um traçado que o levava inexoravelmente ao contemporâneo. Um contemporâneo que, para Pedrosa se inscrevia no destino da abstração (REINHEIMER, 2013) e cuja necessidade o crítico já atribuíra em 1953 ao percurso em direção à autonomia. Dizia ele, então:

Cézanne pressentiu o que era a realidade artística, e reclamou para o artista o direito de descobrir nas coisas sua "pequena sensação". O cubismo deu à obra realizada uma dignidade nova, e a tela cubista é um universo em si, com suas leis, seus acontecimentos. A arte abstrata coroa esse longo processo de conquista da autonomia do fenômeno artístico, dispensando o objeto ou conservando dele apenas o rastro no espaço (PEDROSA, 1996, p.244).

Se em 1959 Brasília se punha também como coroamento da síntese nas artes, se colocando como forma a intervir concretamente na realidade e formulando um destino de país condenado ao moderno, nos anos que se seguiram Pedrosa parecia crescentemente preocupado com uma forma que, classificada por ele como antiarte ou arte pós-moderna, se dirigia a um “comportamento significativo" (PEDROSA, 1966). Tanto Homenagem a Cara de Cavalo de Hélio Oiticica, como o pop sertanejo de Antônio Dias seriam objeto de reflexão e índices do surgimento de uma nova arte, na qual o discurso era tão imprescindível quanto a forma. 
As sucessivas rupturas no desenvolvimento da arte poriam em xeque a linearidade de processos e, se o desencantamento de Pedrosa com a arte é ainda objeto de intenso debate, fato é que seus projetos posteriores de museu pouco diálogo estabeleceram com aquele que é aqui objeto deste artigo. Em 1978, quando diante do incêndio do MAM e da missão de reformular um projeto de museu, Pedrosa se punha mais uma vez frente a uma realidade de ainda mais profunda escassez de recursos e da falência do projeto das elites que haviam sido destituídas pelo golpe de 1964. É digno de nota, no entanto, que na ocasião, Pedrosa não retome o projeto de um museu de reproduções como havia concebido para Brasília, mas advogue a criação de um Museu das Origens (SANT'ANNA, 2014). O projeto lembrava que o MAM carioca tinha "local e sede magníficos", mas, diante do fogo, estava inteiramente destituído de acervo próprio. Pedrosa sugeria então a junção de cinco museus: o Museu do Índio; um museu para a Arte Virgem, formado a partir do Museu do Inconsciente; o Museu do Negro, a ser constituído "a partir de peças trazidas de África e de obras criadas aqui no Brasil, principalmente nos cultos religiosos, onde são usadas"; o Museu de Artes Populares, composto por "peças colhidas nas várias regiões do Brasil"; e o Museu de Arte Moderna que deveria "reconstituir um acervo que seja antes de tudo representativo da arte brasileira”.

Se, em 1958, Brasília se punha como realização utópica universal que coincidia no pós-guerra com "a necessidade de reconstrução do mundo que se reclama[va] por toda parte" (PEDROSA, 1959b), o museu de reproduções se punha como a narrativa de seu ápice, realização de um Brasil moderno na arte coletiva da forma arquitetônica. Em 1978, no entanto, o incêndio do MAM, acaso distópico de um projeto que fracassava, tornava necessário fazer ressurgir das cinzas um futuro possível, a partir da coetaneidade do não contemporâneo. Em lugar de uma narrativa linear em direção ao futuro, era chegado um momento de impasse e a arte precisava refletir sobre si mesma. O projeto de um Museu das Origens se colocava, portanto, numa chave de renovação, em que mais uma vez a arte poderia servir para transformar experiências, não mais remetendo ao futuro, mas encontrando num mundo originário um vínculo afetivo capaz de, para Pedrosa, mudar um sistema capitalista em decadência que era também tragédia da cultura (SANT'ANNA, 2019). 


\section{Dois contrapontos: O projeto de Museu das origens e o Museo de la Solidaridad.}

Aproximadamente vinte anos depois da proposta de instalação de um museu de reproduções em Brasília, Pedrosa volta a público para apresentar um novo projeto que envolveria a organização do chamado "Museu das Origens". A proposta de 1978 é retomada aqui tendo em vista um olhar comparativo em relação ao museu planejado para Brasília. Cabe perguntar as razões pelas quais as ideias que constituíam o museu de reproduções parecem ser abandonadas e substituídas, deixando de lado uma leitura sobre a história da arte que parecia privilegiar a arte abstrata como força pedagógica.

Claro que as circunstâncias mais imediatas em torno dos dois projetos possibilitam algumas conjecturas acerca do sentido atribuído por Pedrosa às duas instituições ao serem propostas. O museu de reproduções foi imaginado como parte do projeto da nova capital brasileira, que foi visto por Pedrosa com um relativo otimismo e como uma oportunidade para o desenvolvimento brasileiro. Já o Museu das Origens foi concebido como uma reação ao trágico incêndio do MAM. Mas outras condições parecem mais determinantes para entender as diferenças entre os papéis desempenhados pelos dois museus.

O projeto de 1978 idealizava o Museu das Origens como uma unidade constituída por cinco museus "independentes mas orgânicos" (PEDROSA, 1978a): Museu do Índio, o Museu da Arte Virgem (do Inconsciente), Museu de Arte Moderna, o Museu do Negro, o Museu de Artes Populares. Como afirmado por Pedrosa, essa nova instituição não deveria tentar imitar o MAM ou seguir os mesmos passos que levaram a sua origem. Segundo ele, o tempo, a filosofia e até mesmo a ideologia que inspirou a constituição do museu ao final da década de 1940 já eram outros em 1978. Diante da destruição de boa parte do acervo, Pedrosa via a parceria entre poder público, gestores privados e sócios do MAM como única forma de estabelecer essa nova instituição e constituir um novo acervo.

Há em tal proposta certa conveniência, já que ela permitiria constituir um novo acervo mais rapidamente e com custos menores. Mas é evidente que não foi tal dimensão prática o principal elemento que condicionou o novo projeto de museu 
idealizado por Pedrosa. Como afirmado por ele em entrevista realizada pela FUNARTE cerca de um ano depois da proposta de Museu das Origens, Pedrosa aponta que sua intenção ao apresentar o projeto estava ligada ao seu entendimento sobre a crise da arte moderna. Nesse sentido, esse novo museu não deveria despender um esforço colossal para comprar novos Picassos e Matisses, mas sim procurar constituir um acervo que "que realmente fosse representativo do que havia de cultura ou de criativo neste país” e que fosse capaz de mostrar aos brasileiros e aos visitantes estrangeiros que o Brasil "não é um país anônimo, um país que segue as regras do que se faz em Nova Iorque ou Paris sem nenhum mais respeito de ligação com as raízes deste país” (PEDROSA, 1979b). Pedrosa via tais raízes não como uma bravata patriota, mas como um elemento de iniciação e de identidade que poderia ter mais importância no presente contexto do que qualquer modernismo, que, segundo ele, deveriam ser esquecidos para que o Brasil pudesse "baixar ao chão e tirar lá de dentro os tesouros que estão lá e que nós não soubemos mostrar nem utilizar” (PEDROSA, 1979b).

A defesa de tais artes "originais” entre as inquietações presentes na crítica de Pedrosa não é uma novidade. Mas o que parece ocorrer ao final da década de 1970 é uma profunda mudança de ênfase, em que as pesquisas sobre a capacidade comunicativa da arte moderna a partir das experiências estéticas não mediadas por uma tradição eurocêntrica perdem lugar para um retorno às "raízes" de uma arte brasileira intocada. Tal mudança de perspectiva já pode ser observada pela primeira vez nos planejamentos para a exposição "Alegria de Viver, Alegria de Criar”, proposta por Pedrosa logo após seu retorno ao Brasil, em 1977, (REINALDIM,2019) e que pode ser entendida como fruto das experiências de seu exílio no Chile. Mas mesmo enquanto esteve envolvido na construção do Museo de la Solidaridad, Pedrosa ainda não atribuía a este um papel de resgate de nenhuma “origem” ou tradição em especial. O Museo de la Solidaridad foi concebido como uma forma de angariar atenção mundial e apoio ao projeto socialista idealizado por Allende. Isso foi feito, sobretudo, pela doação de artistas modernos de todo o mundo, sem estabelecer uma divisão entre arte moderna e artes originais.

Em 1971, quando Pedrosa já estava envolvido na construção do projeto socialista chileno, ele ainda afirmava que o ponto de entrecruzamento entre a arte e o 
socialismo estaria no esforço para "recriar as condições para que a arte seja outra vez como foi em épocas remotas, nas velhas sociedades pré-capitalistas, uma necessidade coletiva, o que hoje, sobretudo nas sociedades de economia de mercado não, sendo simplesmente uma atividade elitista" (PEDROSA, 1995b, p.320). Ainda perdurava no período uma crença no poder transformador da arte moderna semelhante àquela presente no projeto do museu de reproduções. Tais obras não serviriam apenas como uma propaganda do governo Allende, assim como o museu de reproduções de Brasília não pretendia ser uma propaganda do governo Kubitschek. Vislumbrava-se uma real contribuição ao potencial criativo do povo chileno, possibilidade esta que só se cumpriria na medida em que estas obras se tornassem um patrimônio do povo chileno, acessível a todos e distribuído em um espaço construído com o único intuito de potencializar as experiências comunicativas e a possibilidade de reflexão ${ }^{10}$ sobre aquilo que foi vivenciado através das obras dos artistas modernos irmanados com a causa socialista chilena. Como colocado por Pedrosa em maio de 1972, em ocasião da inauguração do Museo de la Solidaridad:

Agora encerrada nessas salas, pendurada em suas paredes, já está
materializada a ideia sob cujo valor enobrecedor nos encontramos, juntos,
aqui. Essa materialização é a arte em seu processo de manifestação. Além de
olhá-las, contemplá-las, admirar essas peças vivas e corpóreas, de dialogar
com elas pelo tato, pelos sentidos, pelo pensamento, adquirimos uma nova
experiência de vida, um novo enriquecimento cognitivo, que é sobretudo, um
veículo da Verdade, ainda transcendente em seu contraste com uma realidade
que a nega. E enquanto a realidade permaneça negando-a, a arte continua em
sua permanente aproximação a uma verdade cada vez mais histórica, e cada
vez menos transcendente. Um dia, num ponto do horizonte, os dois processos
se encontrarão, e então a arte será vida, e a vida será arte. Desse otimismo
vivem os homens da ação, que acreditam no futuro, e querem forjá-lo com
progresso e bem-estar; e desse otimismo vivem os artistas, que são os homens
da imaginação, que querem cria a felicidade humana sobre a terra (PEDROSA,
2013, p.99).

${ }^{10}$ Como colocado por Cáceres, o "Museu de Arte Moderna e Experimental" imaginado por Pedrosa para receber as obras dos artistas que colaborassem como o projeto chileno "consistia na concepção de museu como espaço reflexivo onde o público e o artista teriam um espaço de aprendizagem em contato com as obras de diversos períodos históricos e, a partir da criação de um ambiente reflexivo seriam levados a perscrutar as novas formas possíveis que a arte poderia adquirir mantendo certo sentido originário da atividade: dar forma ao mundo ao mesmo tempo em que se dá forma à sensibilidade humana (CÁCERES, 2010, p.97). 
Mas há de se perceber também que uma idealização romântica" ${ }^{11}$ de um passado pré-capitalista esteve presente em boa parte do pensamento pedrosiano ao longo de sua trajetória. Esse fenômeno não é exatamente raro na história do marxismo e pode ser observado, destacadamente, nos autores alemães cujo interesse analítico recaia nas questões culturais, como György Lukács, Ernst Bloch, Walter Benjamin, Herbert Marcuse e outros dos vinculados à chamada "Escola de Frankfurt" (LOWY \& SAYRE, 1995, p.126-127). Ainda que tal pré-capitalismo idealizado fosse apresentado como forma de conter a crescente mercantilização da arte desde meados da década de 1960, a posição de Pedrosa enquanto esteve no Chile ainda estabelecia como ponto nevrálgico de qualquer transformação cultural orientada pelo socialismo a atuação do artista que, ao se conscientizarem das contradições entre as práticas artísticas e os condicionamentos impostos pelo capitalismo, buscariam no exercício da própria arte "livrar-se dessas modalidades de servidão" e servir como "implacáveis acusadores e testemunhas a favor da causa do nosso modelo socialista" na medida em que “denunciam por suas atividades e por suas 'obras' os males e impasses a que foram levados por sua sociedade" (PEDROSA, 1995b, p.318). Em tal modo de perceber a atuação do artista em prol de uma transformação social, Pedrosa ainda se mostra um adepto da defesa das capacidades comunicativas da arte e permanece dando ênfase ao papel exercido pelo artista moderno ao pensar no sentido antecipador e transformador que as "especulações estéticas" destes ganham no contexto capitalista. Contudo, aqui ele já teria deixado de lado a preeminência do abstracionismo geométrico enquanto forma privilegiada. Isso fica claro no prefácio escrito por ele em 1972 para a coletânea de artigos "Mundo, homem, arte em crise". Escrito enquanto Pedrosa ainda estava em Santiago, o prefácio apresenta a função comunicativa da arte e sua função social no contexto do "alto capitalismo" como enfoques pertinentes para a abordagem dos problemas estéticos-sociais que atingem a condição de produção artística do período. Porém, Pedrosa também observava que não havia "mais nada a extrair" do

\footnotetext{
${ }^{11}$ Segundo o sentido atribuído ao termo por Lowy e Sayre, romantismo pode ser definido uma "visão do mundo [que] constitui-se enquanto forma específica de crítica da "modernidade" (LOWY \& SAYRE, 1995, p.35) em que o teor de tal crítica está ligada à "convicção dolorosa e melancólica de que o presente carece de certos valores humanos essenciais que foram alienados" (LOWY \& SAYRE, 1995, p 40). Assim, tal atitude romântica é marcada por uma nostalgia que "incide sobre um passado précapitalista" que pode ser "inteiramente mitológico ou legendário" (LOWY \& SAYRE, 1995, p 40-41).
} 
abstracionismo geométrico ou de quaisquer outras das designações que eram, à época, atribuídas à arte abstrata em razão. Para Pedrosa, a arte de seu tempo, uma "arte dita moderna”, era uma arte que "arquejava” em razão da crise estético-social estabelecida pelo desenvolvimento da sociedade de consumo (PEDROSA, 1975, p.8).

A posição de Pedrosa só parece se direcionar àquela que se pronunciaria com o projeto de Museu das Origens a partir do fim da breve experiência socialista chilena, violentamente encerrada em razão do golpe militar de 11 de setembro de 1973. Depois de ter sofrido perseguições políticas no Brasil e no Chile e ser forçado a se retirar em exílio dos dois países, Pedrosa passa a expressar mais diretamente um esgotamento das possibilidades transformadoras pela via da arte moderna. É inegável que há nos escritos de Pedrosa um retorno às questões políticas e certa decepção com os rumos tomados pela arte. Após a sua fuga do Chile em direção à França, onde passou os últimos anos de seu exílio até o seu retorno ao Brasil em 1977, Pedrosa começa a redação das “Teses do Terceiro Mundo", em que aborda a crise que assolaria não apenas a arte, mas o mundo inteiro, mas cujo peso recairia, sobretudo, no terceiro mundo, afligido pelo imperialismo e seus males. A crise do capitalismo também atingia os países desenvolvidos naquele período, mas era nos países em sua periferia que tal crise toma a forma de um descontentamento político generalizado que põe em questão a própria ordem econômica capitalista e as instituições políticas que esta impunha ao sul global, exemplificada no texto pela ditadura de Pinochet e outros. Depois de "mais de duzentos anos de capitalismo e mais de cem anos de imperialismo predatório", a lógica perversa imposta aos países do hemisfério sul toma a forma de um único "grande" ideal: "o mínimo de organização para que (...) possam matar a sua fome” (PEDROSA, 1978b, p.17).

Pedrosa via nos crimes do imperialismo exatamente a ruína de todas as velhas culturas pré-capitalistas e é em tal chave que a proposta de Museu das Origens pode ser lida. A queda do projeto socialista de Salvador Allende pôs fim às esperanças civilizatórias que Pedrosa depositara na arte moderna, que em 1975 já era resumida por ele como mais um dos “aparelhos ideológicos' em que se apoia o poder da burguesia” (PEDROSA, 1995c, p.321). Retomando, em parte, uma perspectiva mais frequente em seus escritos da década de 1930, Pedrosa parece, mais uma vez, rejeitar a arte burguesa 
- vista como aquela que "reivindica para si toda a criatividade toda a criatividade humana”, transformando-os "em valores de troca” - e os museus inseridos em sua lógica - que colaboram com tal intento ao "consagrar" as obras neles expostas para assim "subir às nuvens" seus preços e de outras do mesmo autor ou estilo, aos modos de um mercado de ações (PEDROSA, 1995c, p.322). Em suas acusações, Pedrosa atribuía ao informal e à pop art o fim da arte moderna, pois estabeleciam uma recusa aos valores plásticos, formais e estéticos que a caracterizavam (PEDROSA, 1995C, p.325). Nesta nova fase de seu pensamento estético, no entanto, sua recusa à arte burguesa não recai apenas sobre tais tendências, já que ele colocava não apenas estas, mas também a arte minimalista, a arte conceitual e até mesmo as expressões contemporâneas da arte abstrata como expressões de um consumo conspícuo, fruto de uma "mistificação cultural" que se reproduz e se projeta como "bens supremos que os grandes monopólios (...) transnacionais levam para todo o mundo, principalmente para os países da periferia, como os emblemas, os símbolos da civilização cosmopolita do global shopping center a que os sumo-sacerdotes das gigantescas empresas monopolistas querem reduzir o planeta" (PEDROSA, 1995c, p.326).

Mas em contraponto a tal visão pessimista sobre a possibilidade emancipatória da arte moderna, Pedrosa também reforça aquilo que chamamos aqui de um "romantismo" em relação às práticas artísticas que remetem às sociedades précapitalistas, que se manifestam nas práticas dos povos tradicionais denominadas em sua maioria como "arte popular" ou "artesanato". A partir desse ponto de vista, o artista recupera uma posição transformadora e revolucionária na medida em busca de um “retorno (...) à condição de artesão" (PEDROSA, 1995c, p.326) que não deve ser confundida como uma resposta ao gosto pelo exótico e folclórico do colonizador, mas sim como um artesanato que "contribui para romper a estrutura de classes e põe em questão o monopólio da atividade criadora da burguesia” (PEDROSA, 1995c, p.328). Tal artesanato de caráter revolucionário é exemplificado nas cooperativas de artesãos formadas no Chile durante o governo Allende, que teriam estabelecido não apenas novas formas de renda para estes trabalhadores, mas também uma nova autonomia na organização do trabalho, um restabelecimento da liberdade criadora, a criação de um novo público e a transformação dos gostos. Na medida em que avança em direção à 
"destruição" dos valores de classe burgueses e contribui para a "desalienação cultural", que atinge aos países latino-americanos, tal artesanato ganharia, segundo Pedrosa, um sentido revolucionário (PEDROSA, 1995c, p.330). E é também nesse sentido que Pedrosa passaria a promover, já de volta ao Brasil, em 1978, um museu que resgatasse tal caráter artesanal dormente na sociedade brasileira.

É neste contexto que se estabelece a nova interpretação sobre a condição de exercício da prática artística que orientou o projeto do Museu das Origens. A notável diferença entre o projeto de 1978 e aquele imaginado por Pedrosa cerca de 20 anos antes e que deu forma à proposta do museu de reproduções poderia ser facilmente justificado como uma decepção em razão de todas as lutas perdidas e pela emergência da crise mundial que se aprofundou ao longo da década de 1980. É inegável que o fato de Pedrosa ter vivenciado em menos de uma década dois golpes de estado e de ter sido perseguido, já aos setenta anos de idade, pela ditadura brasileira e chilena acabou por afetar o seu julgamento sobre arte do seu tempo. Em tais condições, não é uma surpresa notar um pessimismo e um viés mais ríspido em relação às possibilidades emancipatórias. Seria compreensível se Pedrosa optasse em deixar de lado as questões estéticas para retomar aos seus escritos políticos e sua militância socialista. De fato, Pedrosa, se voltou novamente para as questões políticas, mas sem abandonar sua reflexão sobre a condição do artista na sociedade capitalista, até mesmo porque essas dimensões estavam intrincadas ao longo de toda a sua trajetória. E mesmo que este tenha apresentado clivagens significativas em relação às posições defendidas por Pedrosa durante as décadas de 1950 e 1960, também existem continuidades significativas e são exatamente estas que nos ajudam a compreender a proposta do museu das reproduções projetado para Brasília e o sentido desta instituição em seu pensamento estético.

Já aos 78 anos de idade, Pedrosa ainda acreditava, assim como em 1958, na potencialidade revolucionária da arte. Essa crença perdurou desde a década de 1930 e permaneceu intacta até sua morte, em 1981. Tal potencialidade sempre foi ancorada na crença na capacidade da arte em proporcionar um alargamento das sensibilidades e das competências cognitivas daqueles que incorporam em suas vidas a vivência de experiências criadoras. Mas o que se transforma nessa última etapa do pensamento 
pedrosiano em artes são os sentidos e as formas como possibilitar a construção dessa nova consciência, o que é estabelecido não apenas pelas decepções e pelas dificuldades enfrentadas por Pedrosa ao longo da década de 1970, mas, fundamentalmente, pelas profundas transformações que atingiram o mundo das artes nas últimas décadas do século XX. Assim, o Museu das Origens, assim como o Museu de Brasília, são expressões das interpretações feitas por Pedrosa acerca das condições materiais de produção de arte e de sua determinação a partir do modo de produção capitalista de seu tempo. Se no período ao qual se refere o Museu das Origens, a possibilidade ação emancipadora da arte estaria naquilo que Pedrosa chamou de "arte de retaguarda", no período em que Pedrosa mobilizou seus esforços pela adesão do Museu de Reproduções ao conjunto arquitetônico que constituía a nova capital, tal possibilidade ainda era vista na experiência e na vivência com a forma moderna. Como a própria cidade era fruto de tal idealização transformadora da especulação estética transfigurada na arquitetura de Brasília, a vivência proporcionada pelo Museu de reproduções deveria ser de outro tipo, mas complementar à unidade que constituía a nova capital.

\section{Considerações finais: museus e experiência}

Aproximadamente dois anos antes de apresentar ao público os treze pontos que alicerçaram o Museu de Reproduções, ao responder à "enquête sur l'art magique" de André Breton, Pedrosa traçara um paralelo entre a arte moderna e o pensamento mítico, em que a arte é entendida como “o maior e mais profundo esforço do pensamento e da sensibilidade ocidental para recuperar o espírito, mágico ou, pelo menos, para retornar aos modos, do pensamento mítico, caído em desuso com o advento do racionalismo metafísico da civilização utilitária burguesa”. Se na última fase de sua crítica, Pedrosa parece retomar a questão do pensamento mítico como esperança de um restabelecimento entre arte e vida, no período em que Pedrosa elaborou o projeto de museu de reproduções, Pedrosa ainda via na arte abstrata e na sua inerente incomunicabilidade pela via da linguagem discursiva "um convite a esse retorno recuperativo" de uma dimensão mágica. Nesta perspectiva, a arte abstrata 
cumpriria não apenas sua função comunicativa, mas também sua função social, ao convidar o público que deseja compreendê-la, a "pôr de lado o aparelho um tanto rígido ou especializado de nossos conceitos lógicos” para tornar possível o acesso a uma "atitude mental e espiritual diferente da que governa as relações intelectuais e sociais dos homens em nossa sociedade ocidental" (PEDROSA, 1956).

Neste sentido, o museu desempenharia, em primeiro lugar, o papel de estabelecer meios de acesso facilitado às obras a que eram atribuídas uma capacidade comunicativa privilegiada, seguindo a narrativa linear idealizada por Pedrosa. Isso só foi possível em razão dos avanços tecnológicos que tornaram possível reproduzir imagens dos diferentes períodos históricos de maneira fiel. Mas o museu de reproduções também desempenharia uma outra função, baseada na sua espacialidade apartada dos fluxos contínuos da vida e na sua potencialidade para servir como espécie de "função ritual". Nesse sentido, o museu também deveria ser um espaço de ruptura com a vida urbana, com o "mecanismo do cotidiano" que impede a apreciação das coisas "direta e imediatamente percebidas" (PEDROSA, 1961). Seja no dia-a-dia da vida do trabalhador, na apreciação da cultura de massas e até mesmo nos típicos museus e suas visitas guiadas, há, segundo Pedrosa, a predominância da inferência lógica como modo de apreciação dos fenômenos estéticos. As exigências para que um dado objeto seja percebido artisticamente envolvem certo isolamento e concentração e são as instituições como os museus, apesar de sua precariedade e heterogeneidade, aquelas que melhor cumprem tal função no mundo ocidental.

Não é nova a ideia de que os museus possuem a potencialidade de servir como um espaço de formação moral e espiritual. É um lugar-comum a afirmação de que os museus foram construídos, arquitetonicamente e ideologicamente, como espaços de contemplação de uma arte que, apesar de secular, ganhava contornos de "sagrada" pelo poder imbuído a tais espaços. Mesmo que tais museus, típicos do século XIX, tenham desempenhado um importante papel na sacralização de uma noção de "cultura" combatida por Pedrosa, há um elemento que os aproxima não apenas do caso do Museu de Brasília, mas também dos outros dois projetos museais desenvolvidos por Pedrosa citados aqui: o papel do museu - ou qualquer outra instituição congênere nomeada de maneira distinta - enquanto espaço de liminaridade ritual, elemento 
fundamental para que a experiência possa ser deslocada das expectativas cotidianas (DUNCAN, 2008). A necessidade de o museu ser capaz de cumprir tal função parece ainda mais fundamental nos três projetos pedrosianos, na medida em que todos eles compartilham a noção do museu enquanto forma institucional que é pensada enquanto "lugar privilegiado para essa reeducação não-lógica, mas perceptivoestética", em que cumpriria a sua finalidade na medida em que fosse capaz de "ensinar os visitantes a perceber, direta e imediatamente tudo: quadro, escultura, gravura, espaço, cor, arquitetura" (PEDROSA, 1961). Tal finalidade da forma institucional museu estaria no cerne dos projetos do Museu de Brasília, do Museo de la Solidaridad e do Museu das Origens, alterando-se em cada um dos casos a pertinência dos conteúdos considerados por Pedrosa como necessários de acordo com as demandas de seu tempo.

No caso específico do Museu de Reproduções, Pedrosa propõe que o caráter ritual proporcionado pelo museu seja deslocado, deixando de servir como força para a construção do valor de culto da obra. Em razão do fenômeno que Walter Benjamin chamou de "metamorfose do modo de exposição pela técnica da reprodução" (BENJAMIN, 1987, p.183), os usos sociais do museu poderiam deixar de operar como elemento de reforço da unicidade e de autenticidade da obra de arte - ou seja, como elemento de reforço de sua "aura" - para operar no sentido de possibilitar os deslocamentos necessários para o tipo de experiência estética e pedagógica idealizada por Pedrosa para tal museu. Nesse sentido, as possibilidades políticas vislumbradas por Benjamin ao abordar as artes tecnicamente reprodutíveis parecem aqui transfiguradas por Pedrosa para o caso das artes visuais. Ao mobilizar a função ritual do museu e as técnicas de reprodução tendo em vista o cumprimento do papel pedagógico das artes, não é apenas a arte e a política que se entrecruzam, pois, ao permitir uma experiência direta de comunicação com as obras mais significativas da arte moderna até ali, essa experiência também seria entendida por Pedrosa como um momento de vivência, ainda que breve e fugidio, de uma síntese entre arte e vida.

\section{Referências}

ANDRADE, Mário. Museus populares. Revista Problemas, ano I, no 5, SP, 1938. 
ARANTES,O. Prefácio in: PEDROSA, M. Arte/forma e personalidade: 3 estudos. São Paulo: Kairós,1979.

ARANTES, O. Este Volume. In: (org.). Forma e Percepção estética: Textos Escolhidos II. São Paulo EdUSP,1996.

BENJAMIN, W. A obra de arte na era de sua reprodutividade técnica. In: Obras Escolhidas vol. 1: Magia e técnica, arte e política. São Paulo: ed. Brasiliense, 1987.

CÁCERES, Silvia. Fulguração Moderna: A educação pela arte no Museo de la Solidaridad (Chile,1971-73). Dissertação (Mestrado em Educação) - Pontifícia Universidade Católica do Rio de Janeiro, 2010.

COSTA, Helouise. Museus Imaginários no pós-guerra: o programa da seção de arte da Biblioteca Municipal de São Paulo (1945-1960). Anais do I Seminário Internacional de História da Arte Sérgio Milliet. São Paulo: MAC/USP, 2015.

DIONÍSIO, G. Antídoto do Mal: crítica de arte e loucura na modernidade brasileira. Rio de Janeiro: Ed. FIOCRUZ, 2012.

DUNCAN, C. O museu de arte como ritual. Revista Poiésis, n. 11, p.117-134, nov. 2008.

FORMIGA, Tarcila. À espera da hora plástica: o percurso de Mário Pedrosa na crítica de arte brasileira. 2014. Tese (Doutorado em Sociologia) - Universidade Federal do Rio de Janeiro, 2014.

GUILBAUT, S. How New York Stole the Idea of Modern Art: Abstract Expressionism, Freedom, and the Cold War. Chicago: Univ. Chicago Press, 1983.

GUILLAUME, P. Psicologia da forma. São Paulo: Ed. Nacional, 1966.

GULLAR, F. [carta] 16 fev. 1959, Rio de Janeiro [para] PEDROSA, M. Rio de Janeiro. Acervo Mario Pedrosa. CEMAP-UNESP.

. Entrevista a Nina Galanternick para Formas do Afeto: Um filme de Mario Pedrosa. Arquivo NUSC-UFRJ. Rio de Janeiro. 2008

JAUSS, Hans Robert. A história da literatura como provocação à teoria literária. São Paulo: Ática, 1994.

LANGER, S. K. Philosophy in a New Key: A Study in the symbolism of reason, rite and art. Nova Iorque: Mentor Book, 1954.

LOPES, Fernanda. Área experimental: lugar, espaço e dimensão do experimental na arte brasileira dos anos 1970. São Paulo Prestígio editorial, 2013. 
LÓPEZ, Matias. Ideologia e utopia no Chile: os usos sociais do exílio e da arte. Cadernos de Pesquisa Interdisciplinar em Ciências Humanas. Florianópolis: UFSC 2010.

LÖWY, M.; SAYRE, R. Revolta e melancolia: o romantismo na contramão da modernidade. Petrópolis: Paz e Terra, 1995

LOURENÇO, Maria Cecília F. Museus à grande. Revista do Serviço do Patrimônio Histórico e Artístico Nacional, São Paulo, p. 182-209, 2002.

MALRAUX, André. O Museu Imaginário. Lisboa: Edições 70, 2000.

MAURÍCIO, Jayme. Itinerários da arte. In: Correio da Manhã. o9 out. 1956. Disponível em: <http://memoria.bn.br/docreader/o89842_o6/67722>. Acesso: 14 ago. 2020.

Itinerários da arte. In: Correio da Manhã. o6 ago. 1958. Disponível em: <http://memoria.bn.br/docreader/o89842_06/94681>. Acesso: 14 ago. 2020.

. Itinerários da arte. In: Correio da Manhã. 16 mar. 1959. Disponível em: <http://memoria.bn.br/docreader/o89842_06/103570>. Acesso: 14 ago. 2020.

PEDROSA, M. A força educadora da arte. Correio da Manhã. o6 nov. 1946. Disponível em: <http://memoria.bn.br/docreader/o89842_05/33811>. Acesso: 14 ago. 2020.

O Mundo perdeu seus mitos. Diário Carioca. o9 de novembro de 1947. Disponível em: <http://memoria.bn.br/DocReader/o93092_03/30483>. Acesso: 14 ago. 2020.

Meu Encontro com Malraux. Correio da Manhã. 07 mar. 1948. Disponível em: <http://memoria.bn.br/DocReader/o89842_05/40472>. Acesso: 14 ago. 2020.

. Arte Mágica e o Pensamento Atual. Jornal do Brasil. 23 dez. 1956. Disponível em: <http://memoria.bn.br/DocReader/o30015_07/68941>. Acesso: 14 ago. 2020.

Arte e revolução. Jornal do Brasil. 16 abr. 1957. Disponível em: <http://memoria.bn.br/DocReader/030015_07/72854>. Acesso: 14 ago. 2020.

- Paradoxo Concretista. Jornal do Brasil. 25 Jun. 1959a. Disponível em: <http://memoria.bn.br/DocReader/030015_07/103413>. Acesso: 14 ago. 2020.

Brasília, Cidade Nova. Jornal do Brasil. 19 Jul. 1959b. Disponível em: <http://memoria.bn.br/DocReader/o30015_07/106524>. Acesso: 14 ago. 2020. 
. Museu, instrumento de síntese. Jornal do Brasil. o3 jan. 1961. Disponível em: <http://memoria.bn.br/DocReader/o30015_08/13826>. Acesso: 14 ago. 2020. jun. 1966.

Arte Ambiental, Arte pós-moderna, Hélio Oiticica. Correio da Manhã. 26 _. Prefácio. In: Homem, mundo, arte em crise. São Paulo: Perspectiva, 1975 .

. O Novo MAM terá cinco museus. É a proposta de Mário Pedrosa. In: Jornal do Brasil, 15 set. 1978a. Disponível em: <http://memoria.bn.br/DocReader/o30015_09/186457>. Acesso: 14 ago. 2020.

. Teses para o Terceiro Mundo. In: Encontros com a civilização brasileira. n. 2. Rio de Janeiro: Civilização Brasileira, 1978b.

- Da Natureza afetiva da forma na obra de arte. In: Arte/forma e personalidade: 3 estudos. São Paulo: Kairós, 1979a.

. Entrevista para Projeto Memória INAP/FUNARTE. Rio de Janeiro. 1979b.

. Projeto para o Museu de Brasília. In: ARANTES, O. (org.). Política das artes: textos escolhidos I. São Paulo: Edusp, 1995르.

. O modelo chileno de socialismo e a Frente das Artes. In: ARANTES, O. (org.). Política das artes: textos escolhidos I. São Paulo: Edusp, 1995b.

Arte culta e arte popular. In: ARANTES, O. (org.). Política das artes: textos escolhidos I. São Paulo: Edusp, 1995c.

As relações entre arte e ciência in: ARANTES, O. (org.). Forma e Percepção estética: Textos Escolhidos II. São Paulo EdUSP,1996.

Discurso de inauguração do Museu da Solidariedade. In: OITICICA FILHO, C. Encontros: Mario Pedrosa. Rio de Janeiro: Azougue, 2013.

PUCU, Izabela. Mário Pedrosa: imaginação instituinte, museus e pós-modernidade. In: ; VILLAS BÔAS, Glaucia; PEDROSA, Quito (orgs.). Mário Pedrosa Atual. 1ed. Rio de Janeiro: Instituto Odeon, 2019, v. 1.

QUINDERÉ, N. Pedrosa and Malraux: Impossible Meetings in the Museum of Copies. In: GREET, Michele; TARVER, Gina (orgs.). Art Museums of Latin America: Structuring Representation. Nova Iorque: Routledge, 2018

READ, Herbert. Education Through Art. Londres: Faber and Faber, 1958 
REINALDIM, I. Produção cultural indígena e história da arte no Brasil: exposições e seus enunciados (parte I - Alegria de Viver, Alegria de Criar). MODOS, Revista de História da Arte. Campinas, v. 3, n. 3, p.135-151, set. 2019. Disponível em: $<$ https://www.publionline.iar.unicamp.br/index.php/mod/ article/view/4303 >. Acesso: 14 ago. 2020.

REINHEIMER, P. Cândido Portinari e Mário Pedrosa: uma leitura antropológica do embate entre figuração e abstração no Brasil. Rio de Janeiro: Garamond, 2013.

RIBEIRO VASCONCELOS, Marcelo. O Exílio de Mário Pedrosa nos Estados Unidos e os New York Intellectuals: abstracionismo na barbárie. Tese de Doutorado em Sociologia, Campinas: Universidade Estadual de Campinas, 2018.

A crítica de arte na imprensa carioca e o debate sobre Brasília no congresso da AICA (1959). Teoria e Cultura, Programa de Pós-Graduação em Ciências Sociais UFJF. v. 14 n. 1 Junho. 2019.

ROSENBERG, Harold. The American Action Painters, Art News, vol. 51, no. 8, p.22-23, Dez. 1952.

VILLAS BÔAS, Glaucia. A estética da conversão: o ateliê do Engenho de Dentro e a arte concreta carioca (1946-1951). Tempo social, São Paulo, v. 20, n. 2, p. 197-219, nov. 2008.

SANT'ANNA, Sabrina Parracho. "Pecados de Heresia": trajetória do Concretismo carioca. 2004. Dissertação (mestrado em Sociologia) - Universidade Federal do Rio de Janeiro, 2014.

Construindo a memória do futuro: uma análise da fundação do Museu de Arte Moderna do Rio de Janeiro. 1. ed. Rio de Janeiro: Editora da FGV, 2011.

Presságios e projetos: o incêndio do MAM e os rumos da arte contemporânea. Revista VIS (UnB), v. 13, p. 1/14-18, 2014.

Mário Pedrosa e as Musas: reflexões sobre crítica e projetos museais. In: PUCU, Izabela; VILLAS BÔAS, Glaucia; PEDROSA, Quito (orgs.). Mário Pedrosa Atual. 1ed. Rio de Janeiro: Instituto Odeon, 2019, v. 1, p. 373-413. 